\title{
Looking at the Origin: Some Insights into the General and Fermentative Microbiota of Vineyard Soils
}

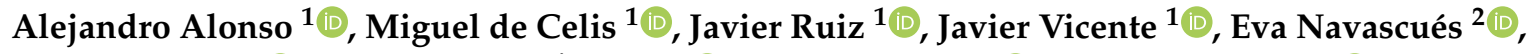

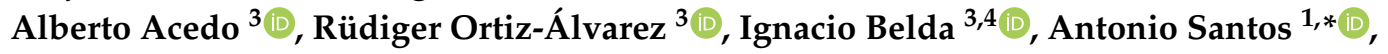 \\ María Ángeles Gómez-Flechoso ${ }^{5}(\mathbb{D})$ and Domingo Marquina ${ }^{1}$ (D) \\ 1 Department of Genetics, Physiology and Microbiology, Unit of Microbiology, Biology Faculty, \\ Complutense University of Madrid, 28040 Madrid, Spain \\ 2 Pago de Carraovejas, S.L.U., Camino de Carraovejas, s/n, 47300 Peñafiel, Valladolid, Spain \\ 3 Science Department, Biome Makers Spain, 47011 Valladolid, Spain \\ 4 Department of Biology, Geology, Physics \& Inorganic Chemistry, Unit of Biodiversity and Conservation, \\ Rey Juan Carlos University, 28933 Móstoles, Spain \\ 5 Departament of Earth Physics \& Astrophysics, Physics Faculty, Complutense University of Madrid, \\ 28040 Madrid, Spain \\ * Correspondence: ansantos@ucm.es; Tel.: +34-913-944-962
}

Received: 8 July 2019; Accepted: 27 August 2019; Published: 29 August 2019

\begin{abstract}
In winemaking processes, there is a current tendency to develop spontaneous fermentations taking advantage of the metabolic diversity of derived from the great microbial diversity present in grape musts. This enological practice enhances wine complexity, but undesirable consequences or deviations could appear on wine quality. Soil is a reservoir of important microorganisms for different beneficial processes, especially for plant nutrition, but it is also the origin of many of the phytopathogenic microorganisms that affect vines. In this study, a meta-taxonomic analysis of the microbial communities inhabiting vineyard soils was realized. A significant impact of the soil type and climate aspects (seasonal patterns) was observed in terms of alpha and beta bacterial diversity, but fungal populations appeared as more stable communities in vineyard soils, especially in terms of alpha diversity. Focusing on the presence and abundance of wine-related microorganisms present in the studied soils, some seasonal and soil-dependent patterns were observed. The Lactobacillaceae family, containing species responsible for the malolactic fermentation, was only present in non-calcareous soils samples and during the summer season. The study of wine-related fungi indicated that the Debaryomycetaceae family dominates the winter yeast population, whereas the Saccharomycetaceae family, containing the most important fermentative yeast species for winemaking, was detected as dominant in summer.
\end{abstract}

Keywords: meta-taxonomic analysis; vineyard soil; wine-related bacteria; wine-related fungi

\section{Introduction}

Microorganisms are very successful inhabitants of the soil due to their adaptability and plasticity to cope with adverse conditions [1]. There is a general assumption that, in many ecosystems, a high biodiversity enhances stability and productivity, and it is regulated by climate, soil properties and soil management aspects [1-3]. Since most biodiversity-productivity studies focus on plant diversity, this relationship requires a better understanding within the microbial populations inhabiting soils, as microorganisms play a crucial role in many key ecosystem functions involved in soil fertility [4-6]. Plants are dependent on the growth of soil microbes, which possess the metabolic machinery to access soil nutrients such as N, P, and S that, usually, are minimally bioavailable for them [7]. With hundreds 
to thousands of taxa per gram of soil, it has been demonstrated that functional redundancy within the soil microbial community is high, indicating that microbial community diversity is dissociated from functioning [8,9]. Such evidence is considered to be highly relevant to infer the impact of climate changes and anthropic practices on soil microbial diversity and, in consequence, biogeochemical cycles in soils [6].

As indicated above, microbial communities are associated with plants, playing a role in soil productivity but also causing phytopathogenic diseases [10]. Numerous studies concerning soilborne microorganisms have been carried out, however, taking into consideration the agricultural, industrial, alimentary and economic implications of soil microorganisms, the development of new tools and approaches for determining their diversity and functions in soils is a continuous task [11].

The interface between roots and soil is probably the most important interaction between plants and their environment [12]. Soil microbes that colonize the plant at the root can move through the plant to colonize the rest of the tissues, promoting plant health or causing different diseases. To help the plant microbiome fight against pathogens, microorganism inoculation has been used in several crops, including vineyards, in an attempt to control plant pathogens using biological agents $[11,13,14]$. Moreover, the possibility that plant inhabiting microorganisms could influence the flavor and productivity of grapes, impacting the organoleptic characteristics of wine, has been reported [12]. On the other hand, one aspect of the relationship between plants and microorganisms that remains unclear is whether soil microorganisms could be related with postharvest processes, such as fermentative ones, including those related to the production of wine.

With the current tendency to recover past practices in winemaking, the wine industry is now frequently producing wines by spontaneous fermentation. This reformulated enology is emerging and aiming to combine the advantages of spontaneous fermentations with those of monitored fermentations. In such fermentations, the microbiota coming from the vineyard takes the leading role of the fermentation process, being the soil the main reservoir of wine-related microorganisms, inhabiting grape berries and thus the later grape must [15]. In this context, a clear connection has been demonstrated between winery and vineyard fermentative microbiota, with a transference of yeasts from the winery to the surrounding vineyards, influencing the native yeast communities [16-21]. As the number of spontaneous fermentation studies increases, the importance of the autochthonous microbiota of the vineyard studies increases too. Recent studies have indicated that grape and wine microbiome from different grape-growing regions correlate with wine metabolome, suggesting that the grape microbiome may influence regional wine characteristics [22].

To date, few studies have analyzed the relationship between the soil microbiota and its influence on the winemaking processes. Currently, microbiome analyzes start interconnecting multiple "omics" studies, leading to unprecedented opportunities to comprehensively characterize microbial communities and their relationships with their environments or subsequent processes [23]. To understand the crucial roles of microorganisms on the entire winemaking process, we should understand the relationship between vineyard and wine microbiomes, also paying attention to the soil microbiome [24]. The use of soil microbiota as an early predictor of wine terroir is unprecedented and poses a potential new challenge for quality control of wine [24].

This study analyzed the microbial, fungal and bacterial communities inhabiting the soils of different blocks of a unique vineyard, in which a relationship between vineyard and wine microbiota has been observed [20]. Thus, we aimed to determine the influence of soil properties in the inhabitant general and fermentative microbiota, and how it changes in a seasonal comparison: summer against winter. 


\section{Materials and Methods}

\subsection{Site Description and Weather Data}

This research was carried out in a vineyard which belongs to Ribera del Duero Geographical Indication (VCPRD). The entire vineyard covers an area of approximately $1.80 \mathrm{~km}^{2}$ and has a Mediterranean with Oceanic influence climate, corresponding to Csb on the Köppen-Geiger climate classification. The annual mean temperature in this region is $12.1^{\circ} \mathrm{C}$, and the multi-year average precipitation is about $434 \mathrm{~mm}$ (Spanish Meteorological Agency AEMET, 2166Y station). The main landform is of hills formed by calcareous deposition and windy sands, with an altitude ranging from 753 to $900 \mathrm{~m}$. Soil types are comprised of sandy, clayey and calcareous ones. Sandy soils show a sand percentage of $59.8-75.3 \%$. The clayey ones present a clay content ranging $22.5-24.5 \%$ and the calcareous soils have a limestone active fraction of $9.8-11.7 \%$. Generally, the soils studied were fairly alkaline, with $\mathrm{pH}$ values around 8.58 . In some samples, the detected $\mathrm{pH}$ values were higher due to the high percentage of limestone.

\subsection{Soil Sampling}

This study included 36 vineyard soil samples, collected in vineyard plots with sandy, clay and limestone soils. Five samples of sandy soils, two of clay soils and two of calcareous soils were taken. From each sample, a replica was made $30 \mathrm{~m}$ away. Soil samples were taken by previously removing the surface layer of leaves that might be on the ground. The 5-25 cm-depth samples were taken to collect the maximum cellular density [25]. This sampling process was done in two seasons: summer and winter.

\subsection{DNA Extraction and Sequencing}

Soil samples, collected as described, were analyzed following a 16S-ITS metabarcoding strategy for determining bacterial and fungal populations. Samples were stored at $-80^{\circ} \mathrm{C}$ until DNA extraction was performed using different bead-beating cycles based on DNA extraction kits such as DNeasy ${ }^{\circledR}$ Powerlyzer ${ }^{\circledR}$ Powersoil ${ }^{\circledR}$ Kit (Qiagen, Hilden, Germany). Libraries were prepared following the two-steps PCR Illumina ${ }^{\circledR}$ protocol and these were subsequently sequenced on Illumina ${ }^{\circledR}$ MiSeq instrument (Illumina ${ }^{\circledR}$, San Diego, CA, USA) using $2 \times 301$ paired-end reads.

All PCR reactions were prepared using sterilized materials and negative controls were run alongside the samples. In addition, PCR conditions such as number of cycles, annealing temperature, thermocycler and Master-mix composition were done according to the WineSeq ${ }^{\circledR}$ technology procedures. The library was performed using a two-step PCR protocol as described by Feld et al. [26] and Albers et al. [27] and then it was analyzed by amplifying and sequencing the V4 16S rRNA V4 gene region and the ITS1 (ITS) regions using WineSeq ${ }^{\circledR}$ custom primers (patent WO2017096385 [28]).

\subsection{Bioinformatic Analysis}

The raw fastq sequences (available at https:/ data.mendeley.com/datasets/yf5mk58kwz/2) were analyzed using DADA2 algorithm [29] implemented in R pipeline [30]. DADA2 implements an error correction model that allows the differentiation of a single nucleotide [31], giving an amplicon sequence variant (ASV) table as a final output. The reads were truncated at their low-quality ends, forward and reverse paired, and chimeras removed. The total good quality reads were 1,636,020 for bacteria and 2,260,792 for fungi. The taxonomic assignment was performed using the naïve Bayesian classifier implemented in DADA2 using as reference Silva (release 132) reference database [32].

\subsection{Functional Profiles Prediction}

Functional predictions based on representative genomes are a useful tool for the estimation of metabolic potential [33]. Although it has limitations regarding strain-specific functional signatures, 
environmental distributions, or real magnitude of a process, the functional simulations allow the comparison of communities in terms of their predicted functional potential [34]. For that purpose, we applied an adaptation of the Tax4Fun routine [35] using presence/absence of genes rather than a normalized weighted value per taxa (https://sourceforge.net/projects/Tax4Fun2/). To obtain the proportion of each community containing each specific function, we filtered a total of 25 KEGGs (functional orthologs) within 14 metabolic pathways related to carbon, nitrogen, phosphorus and sulfur cycles pathways (Table A2). We estimated the distribution of each metabolism and their mean proportions in the microbial population of each soil sample.

\subsection{Statistical Analysis}

Statistical analysis was performed on $\mathrm{R}$ (version 3.5.1) using the phyloseq package, version 1.26.1 [36] and vegan, version 2.5.5 [37]. Alpha diversity was calculated as estimated community diversity using Shannon index [38] and ANOVA test was used to calculate significant differences among sample groups (Figure 1). Beta diversity (differences between samples) was calculated using Bray-Curtis distance matrix on proportion transformed data $[39,40]$ and permutational multi-variate analysis of variance (PERMANOVA). Non-Metric Multi-Dimensional Scaling (NMDS) was computed from the resulting distance matrices to compress dimensionality into two-dimensional plots (Figure 2). For heat map plots, pheatmap package version 1.0.12 $\mathrm{R}$ was used (Figure 3).

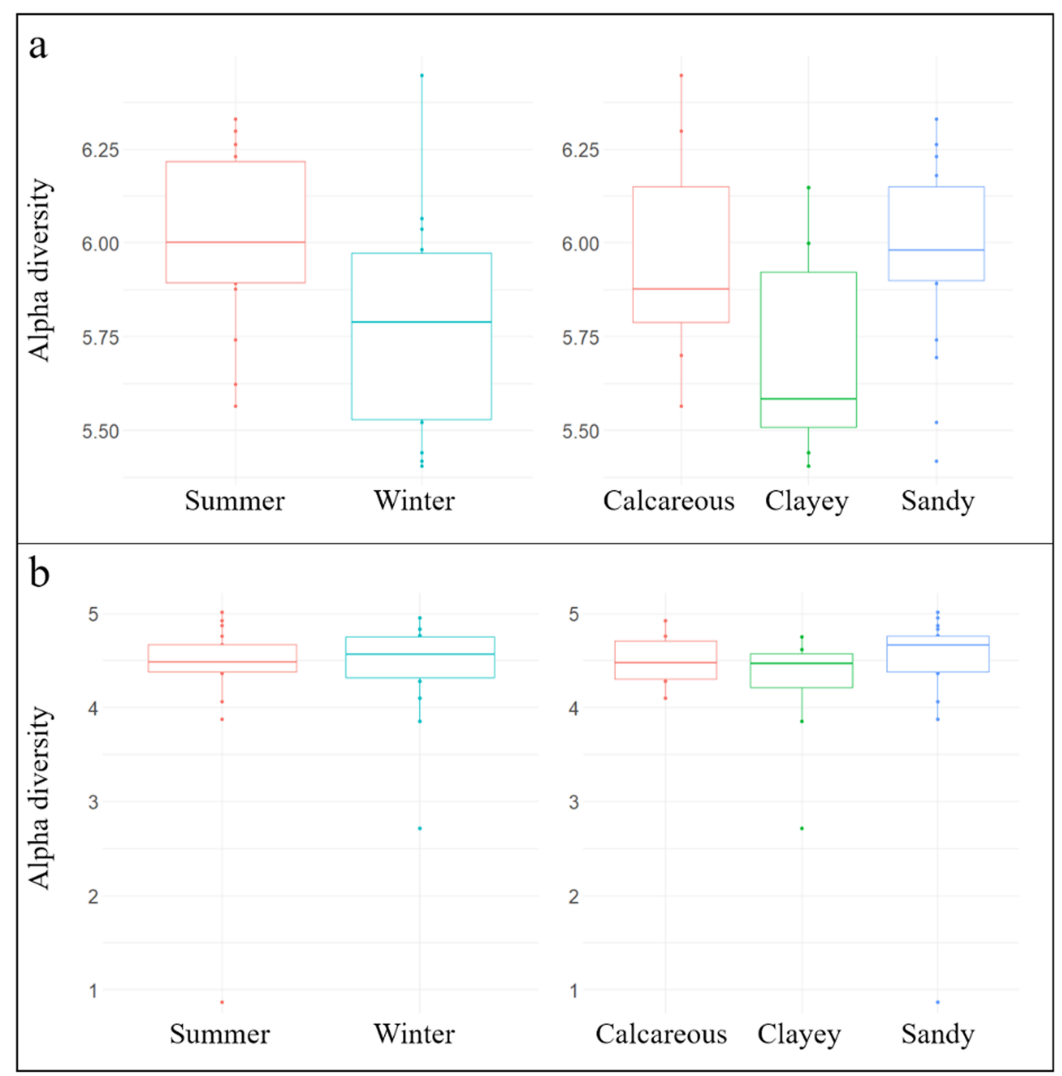

Figure 1. Alpha diversity, measured as Shannon index, calculated on bacterial subset of the dataset $(\mathbf{a})$ showed significant differences $(p$-value $=0.012)$ among seasons, but not among soil types $(p$-value $=0.056)$. When alpha diversity was calculated on the fungal subset of the dataset (b), no statistically significant differences were found for seasons ( $p$-value $=0.716$ ) and for soil type $(p$-value $=0.771)$. 


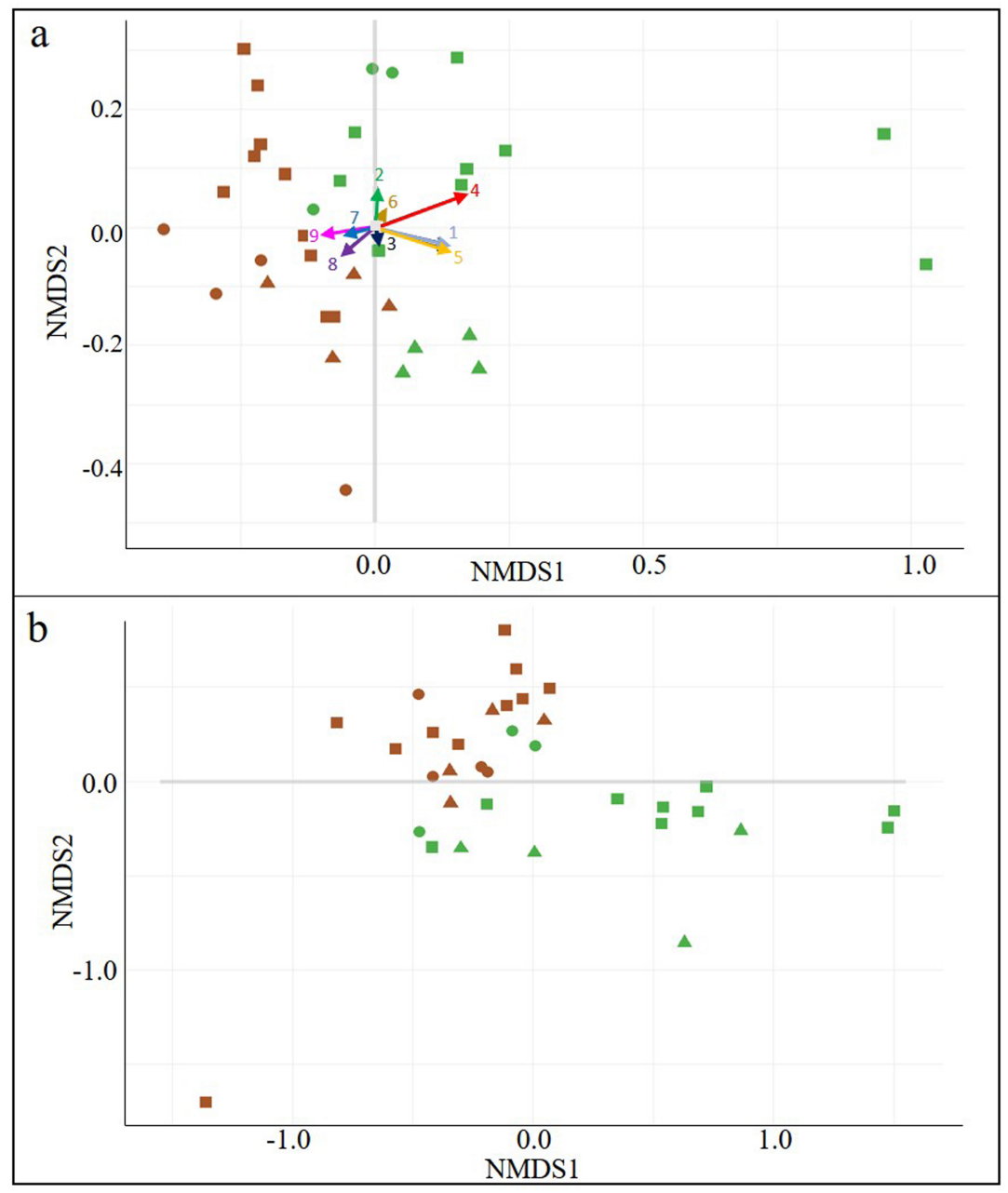

Figure 2. Beta diversity calculated on bacterial (a) and fungal (b) datasets shown in a non-parametric multi-dimensional scale (NMDS) using Bray-Curtis distance. The stress parameter used in the bacterial analysis to define the ordination quality was 0.160 . Significant differences were found among different season samples $(p$-value $=0.001)$ and for samples of different soil types ( $p$-value $=0.058)$. Stress parameter used in the fungal analysis to define the ordination quality was 0.145 . Significant differences were found among different season samples $(p$-value $=0.001)$ and for samples of different soil types $(p$-value $=0.052)$. Seasons (summer (brown) and winter (green)), oil types (calcareous $(\bigcirc)$, clayey $(\triangle)$ and sandy $(\square)$ ). Figure $2 \mathrm{a}$ includes information on the contribution of some bacterial-derived soil-related metabolic functions, inferred from the taxonomical bacterial diversity using the Tax4Fun routine. The nine vectors showed were calculated from the relative abundance of metabolic enzymes (KEGG) corresponding to: (1) carbon organic formation; (2) carbon organic use; (3) nitrogen organic formation; (4) nitrogen organic use; (5) other; (6) phosphorus inorganic transport; (7) phosphorus organic transport; (8) sulfur organic formation; and (9) sulfur organic use. A detailed list of the metabolic enzymes (KEGG) included on each group is reported in Table A2. 


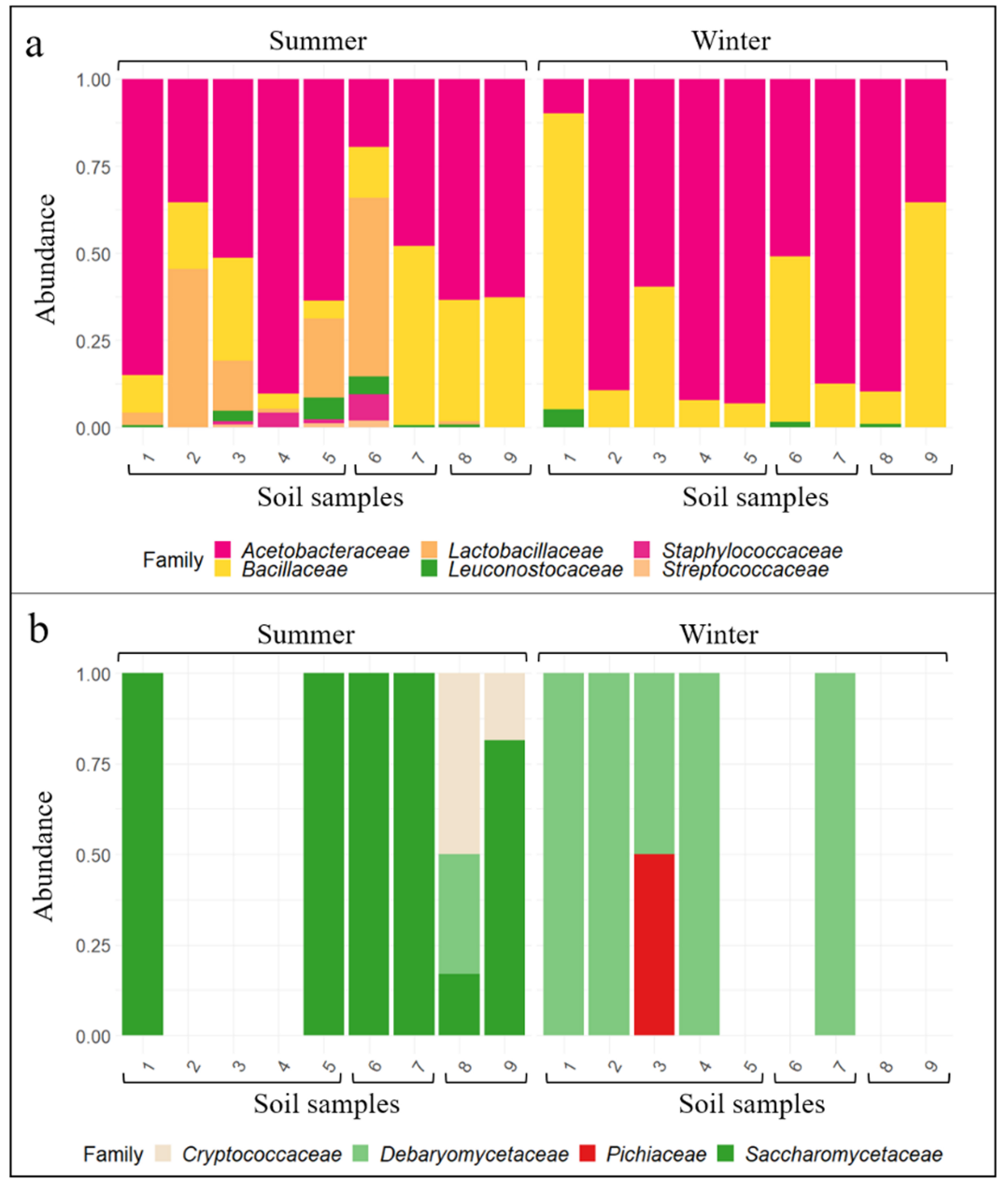

Figure 3. Abundance of wine-related bacterial (a) and fungal (b) families in soil samples and classified according to the soil characteristics (Sandy (1-5), clayey (6-7) and calcareous (8-9)) and the season (summer and winter).

Physical-chemical data of the soil were analyzed by Infostat (C) statistical program [41], using the analysis of main components for the classification of different soils (clay, sandy and limestone) and the subsequent representation of the variables in the two-dimensional principal subspace (Figure A1).

\section{Results and Discussion}

\subsection{General Biodiversity}

There is a general assumption which indicates that the larger the environmental heterogeneity is the larger the diversity of complex organisms is, indicating that more heterogeneous habitats usually present higher species alpha diversity $[42,43]$. However, despite the recognized central role of bacteria in the soils' fertility, less knowledge has been reported concerning the link between the environmental heterogeneity and bacterial diversity $[44,45]$. Several investigations have reported that locations highly different in their environmental and physicochemical parameters usually tend to be very different in their bacterial community composition too [46,47], suggesting that soil heterogeneity increases bacterial beta diversity. Even though the relationship between soil environments and fungal diversity is less known [48], some meta-analysis studies have indicated that, in addition to bacterial alpha diversity, fungal alpha diversity is higher in fields with crop rotations [49] or in temperate deciduous forests [50].

In this study, we analyzed the general microbial diversity (bacterial and fungal population), with the aim of determining the potential connections between soil and wine-related microbiota from 
different vineyards. The microbial diversity as alpha diversity of the vineyard soils was measured using the Shannon index (measure of the species richness and abundance), comparing the effect of two seasons (summer and winter), with very different conditions of temperature and humidity in the sampled region. The climate conditions in the center of Spain are characterized by cold and humid winters, while the summers are hot with very little and occasional rainfall. In addition, the impact of the textural characteristics of the soils (Figure A1) were determined, studying their impact over microbial biodiversity [51] (Figure 1).

The seasonal effect on bacterial alpha diversity changes significantly between seasons. The complexity of bacterial communities has been generally described to be lower in winter than summer [52,53], and our results are in agreement with this observation (Figure 1a). As a result, we hypothesize about the possibility whether the soil bacterial community can be used as a new biological parameter to be considered in vineyard soils zoning strategies in viticulture soils or not. In contrast to bacterial diversity, fungal diversity did not change with the seasons (Figure 1b) and showed a lower Shannon index and greater dispersion than the bacterial subset. The fungal community inhabiting soils was more homogeneous during seasons, maintaining the regional homogeneity of the studied soils. Bacterial populations showed a microscale effect due to their heterogeneity in summer and winter. Although fungi populations could become an indicator of regional character in vineyard blocks.

In this study, we analyzed bacterial diversity as a function of the textural characteristics: calcareous, clayey and sandy soils (Table A1). A lower bacteria diversity was observed in the different types of soil (Figure 1a). Although the differences in the Shannon index among clayey, calcareous and sandy soils using ANOVA test were slightly statistically significant $(p$-value $=0.056)$, it was observed that the Shannon index is different between sandy and clayey soils. No differences were observed in soil types in the fungal subset analyses (Figure 1b).

Beta diversity was calculated as dissimilarity between soil samples, according to the ASVs extracted from the raw data curation process. In the non-parametric multi-dimensional scale ordering (NMDS), the ASVs of the group of bacteria (Figure 2a) and the fungi subset (Figure 2b) show the distances of each soil sample.

The bacterial population separates into two groups defined in the NMDS1 component $(p$-value $=0.001)$. The bacterial subset present in soils in winter was observed for NMDS1 $>0$, approximately. Furthermore, the samples whose bacterial population defined the summer season were located for NMDS1 $<0$ (Figure 2a). The textural characteristics of the soil were also statistically significant $(p$-value $=0.001)$, having NMDS2 $>-0.1$ for sandy soils, approximately, and NMDS2 $<-0.1$ for the other two soils (calcareous and clayey).

Sorting based on stress index for the fungi group allowed separation in the NMDS2 component $(p$-value $=0.001)$. The population of fungi linked to winter were found in NMDS $<0$. In samples collected in summer, the fungal population was observed in NMDS2 $>0$. Statistical analyses of the textural characteristics were also slightly significant $(p$-value $=0.052)$ since this separation was not too clear to define as a function of the NMDS values.

Based on the genomic sequencing of the V4 16S rRNA gene region, it was possible to estimate the functional genes that the bacterial population could express in the soil. The estimated metabolic functions include enzymes involved, among others, in the biogeochemical cycles of carbon, nitrogen, phosphorus and sulfur (vectors at Figure 2a). Based on that, the metabolic routes involved in organic carbon formation, organic nitrogen use and others (see Table A2 for a detailed list of the metabolic routes included) appeared more represented in winter samples. We can hypothesize that this could be because winter samples were collected in January, and a greater concentration of organic matter is accumulated in the soil (coming from fall autumn leaves). On the other hand, summer samples cluster matched the direction of the contribution of metabolic routes involved in sulfur metabolism (organic formation and use). This can be explained as summer samples were collected in early June 
and some routine sulfur-based treatments were applied in April and May for guaranteeing a healthy grape ripening.

Nevertheless, contrary to what was observed at taxonomic (alpha and beta diversity) level, there is not a clear pattern clustering the soils samples coming from different soil types or collected at different seasons (Figure A2). This can indicate that the taxonomic differences found between vineyard blocks are buffered at a functional level due to the high functional redundancy commonly found within soil microbial communities [8,9].

\subsection{Wine-Related Microbial Diversity}

Since the soil has been reported as the main reservoir of microorganisms in the vineyard, and a notable co-occurrence of microorganisms exists among vineyard soils, grapes and musts [15,24], it is of interest to study the presence, diversity and abundance of wine-related bacterial and fungal species in the studied soils. Soil microbiota has been described as important, not only for the chemical and nutritional properties of soils, but also for health, yield, and quality of the grapevine. Apart from being the origin of the fermentative microbiota that will reach the winery as part of the microbial consortia established in the grapes-which would be responsible for positive flavor compounds production or in the production of undesirable molecules (off-flavors, biogenic amines, etc.) - the soil microbiome has been directly co-related with some flavor characteristics of wines (via plant-microbiome interactions), such as the rotundone concentration found in Shiraz grapes from Australian Cool Climate areas [54]. Thus, in response to the current trend of elaborating "single-vineyard" wines as a way to enhance the terroir characteristics of each vineyard block, understanding the microbial signature of soils should be considered in future vineyard zoning works, when trying to define their fermentative potential. The raw data from the sequencing process were filtered, obtaining the abundances of the microorganisms previously described to be isolated from wine-related samples (Table A3).

The WRB found in the meta-taxonomic studies of soils were filtered at the taxonomic level of family due to the limitations showed by the NGS-technique used in this work [55]. The soil samples collected in winter and summer differ in the presence of the family Lactobacillaceae, being of greater presence in summer and absent in winter, while Leuconostocaeae appears in more plots in summer samples. Some examples of species from these families are Oenococcus, Leuconostoc, Weissella (Leuconostocaceae), Lactobacillus and Pediococcus (Lactobacillaceae), mainly responsible for malolactic fermentation [56]. In addition, various species of Lactobacillus, Pediococcus and Leuconostoc can cause spoilage of wine during bulk storage in the cellar and after bottling [57]. No differences were observed by soil type, although in summer calcareous Samples 8 and 9 showed a similar abundance pattern. However, it is possible that in Plots 7-9 the absence of the Lactobacillaceae family was due to an active limestone concentration of more than $5.1 \%$ (Table A1). The pronounced prevalence of the Acetobacteraceae family observed in winter stood out. The ability of acetic acid bacteria to convert ethanol in acetic acid is one of the main sources of wine spoilage. Both grapes and wine are subject to spoilage by this bacteria at different stages of the grape ripening and the winemaking processes [58].

The wine-related fungi (WRF) present in the soils were the Cryptococcaceae, Debaryomycetaceae, Pichiaceae and Saccharomycetaceae families (Figure 4b). However, within some samples, no representatives of these families were found. In summer soils samples from Plots 2-4 and winter samples from Plots 5, 6, 8 and 9, no WRF families were detected. In the summer season, a clear prevalence of the family Saccharomycetaceae was observed in Plots 1,5,6 and 9. Plot 8 did not present fungi of the family Cryptococcaceae and Debaryomycetaceae. Is important to highlight that the calcareous soils of Plots 8 and 9 showing the presence of the WRF family Cryptococcaceae were the only ones that presented this family during summer. In winter, a high frequency of the family Debaryomycetaceae was observed in Plots 1, 2, 4 and 7. The soil of Plot 3 showed the Pichiaceae and Debaryomycetaceae families, which were equally represented. Due to the succession of families Saccharomycetaceae and Cryptococcaceae between summer and winter, WRF seems to be a better indicator for differentiating the seasonal fermentative potential among plots. 
The beta diversity analyzed in the WRB families shows a clear distinction between winter and summer (Figure 4). The component NMDS2 allowed good separation between the variations in the subset of bacteria. The winter samples were mainly arranged in NMDS $<0$, while variations in summer samples qwew disposed in NMDS2 $>0$.

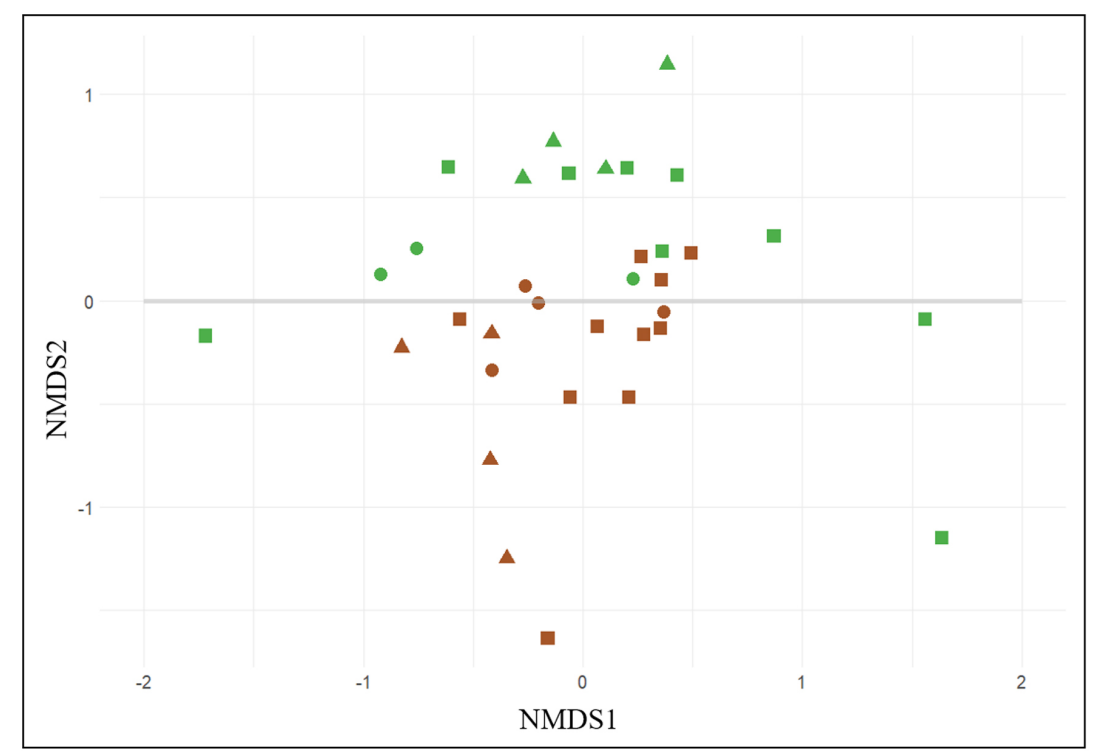

Figure 4. Beta diversity calculated on bacterial datasets shown in a non-parametric multi-dimensional scale (NMDS) using Bray-Curtis distance. Wine related family bacteria exhibited significant seasonal ( $p$-value $=0.001)$ variations in soil samples, but this variation was not evident between soil types $(p$-value $=0.058)$. Seasons $($ summer $($ brown$)$ and winter $($ green $))$. Soil types (calcareous $(\bigcirc)$, clayey $(\triangle)$ and sandy $(\square))$.

\section{Conclusions}

The microbial alpha diversity of the vineyard soils determined in this study varied between seasons (Figure 1), being bacteria a better indicator than fungi in the vineyard zoning and allowing to differentiate the sandy soils from the clayey ones. Furthermore, beta diversity allowed us to separate populations between seasons (summer vs. winter) from bacteria and fungi (Figure 2). The microbial terroir, at a single vineyard scale, could be a tendency in each season, although the bacterial function remained constant (Figure 3). Wine-related bacteria (WRB) remained constant between seasons, except for the family Lactobacillaceae. This family, moreover, was not found in soils with a percentage of limestone higher than $5.1 \%$ (Figure $4 a$ ). Wine-related fungi (WRF) described a summer population dominated by the Saccharomycetaceae family and another winter population represented mainly by the Debaryomycetaceae family (Figure $4 \mathrm{~b}$ ).

\section{Future Perspectives}

Although the relationship between the soil microbiome and in fruit-associated microbial composition is difficult to establish [59], it is possible to indicate that the microorganisms present in the vineyard influence through many routes the vine development and the quality and fermentative potential of grapes [60]. Analyzing the microbial particularities of different blocks of a single vineyard, we here highlight the concept of microbial terroir. Thus, our results can be used as a starting point for future scientific studies and in-field works considering the microbial aspects of soils in vineyards zoning works trying to define homogeneous terroir units. Apart from the direct importance of the microorganisms in soil health and vine yield, in the present work, we tried to establish a parallelism between the microorganisms that can be detected in the vineyard soils (as the main microbial reservoir in agricultural environments) and the microorganisms reported in different studies that could be found 
during wine fermentation. The great inter-blocks variability found here highlights the important of including the biological aspects of terroir for a complete understanding of the enological potential of vineyards. This study represents an advance in the knowledge of how the microorganisms detected in the vineyard environment, mainly present in the microbial reservoir of the soil, that could affect vine and grape development, and, through this, positively or negatively influence the resulting wine. In addition, taking into account that many of these microorganisms are not only detected but could play a role during fermentation, in this study, we identified the abundance of these microorganisms in the soil microbial reservoir. Future studies in this area will go through the analysis of how the presence of a certain microorganism or a particular microbial consortium present in the soil can influence the quality of a wine in a certain way and, how, through the precise use of appropriate viticulture techniques, we can favor or counteract the presence of these microorganisms. Additionally, this type of studies can contribute to the discovery of undetected microorganisms with optimal fermentation properties and, therefore, could be used as new microorganisms in oenology. Furthermore, they could also help to detect microorganisms for the biological control of pests or phytopathogenic fungi that affect the wood of the vine.

Author Contributions: A.A. (Alejandro Alonso), I.B., E.N., A.S. and D.M. were involved in the sampling and experimental design; A.A. (Alejandro Alonso), M.d.C. and M.A.G.-F. performed the formal data analysis; A.A. (Alejandro Alonso), I.B. and A.S. wrote the article; M.A.G.-F., E.N., A.S. and D.M. supervised the project; and E.N., J.R., J.V., R.O.-Á and A.A. (Alberto Acedo) contributed to data acquisition. All authors discussed the results and contributed to the final manuscript.

Funding: Funding for the research in this paper was provided by Pago de Carraovejas Estate Winery (GLOBALVITI, IDI-20160750) and Biome Makers Spain S.L. (IDI-20180120) under the framework of the MINECO CDTI projects (Spanish Ministry of Economy, Industry and Competitiveness, Centre for Industrial Technological Development).

Acknowledgments: Ignacio Belda acknowledges for his postdoctoral "Torres Quevedo" grant (PTQ-16-08253) provided by the Spanish Ministry of Economy, Industry and Competitiveness.

Conflicts of Interest: Eva Navascués is an employee of Pago de Carraovejas Estate Winery. Alberto Acedo is an employee of Biome Makers, and Rüdiger Ortiz-Álvarez and Ignacio Belda developed part of this work employed by Biome Makers

\begin{tabular}{|c|c|}
\hline \\
\hline \multicolumn{2}{|c|}{$\begin{array}{l}\text { Abbreviations } \\
\text { The following abbreviations are used in this manusc }\end{array}$} \\
\hline ASV & amplicon sequence variant \\
\hline ITS & internal transcribed spacer \\
\hline NMDS & non-parametric multi-dimensional scale \\
\hline PCA & principal component analysis \\
\hline VCPRD & a quality wine psr \\
\hline WRB & wine-related bacteria \\
\hline WRF & wine-related fungi \\
\hline
\end{tabular}

\section{Appendix A. Soil Compositional Characteristics}

For this analysis, the database of physical-chemical parameters of the vineyard soils was used (http: //dx.doi.org/10.17632/yf5mk58kwz.2\#file-0a4b4597-abb7-4df9-96f3-3ea7f44e5cd5). The eigenvectors that implied a greater explanation in each component were analyzed and then the most relevant variables were taken. The statistical on PCA test (Figure A1) allowed classifying by means of different percentages of sand, clay and limestone in the soil (Table A1). 


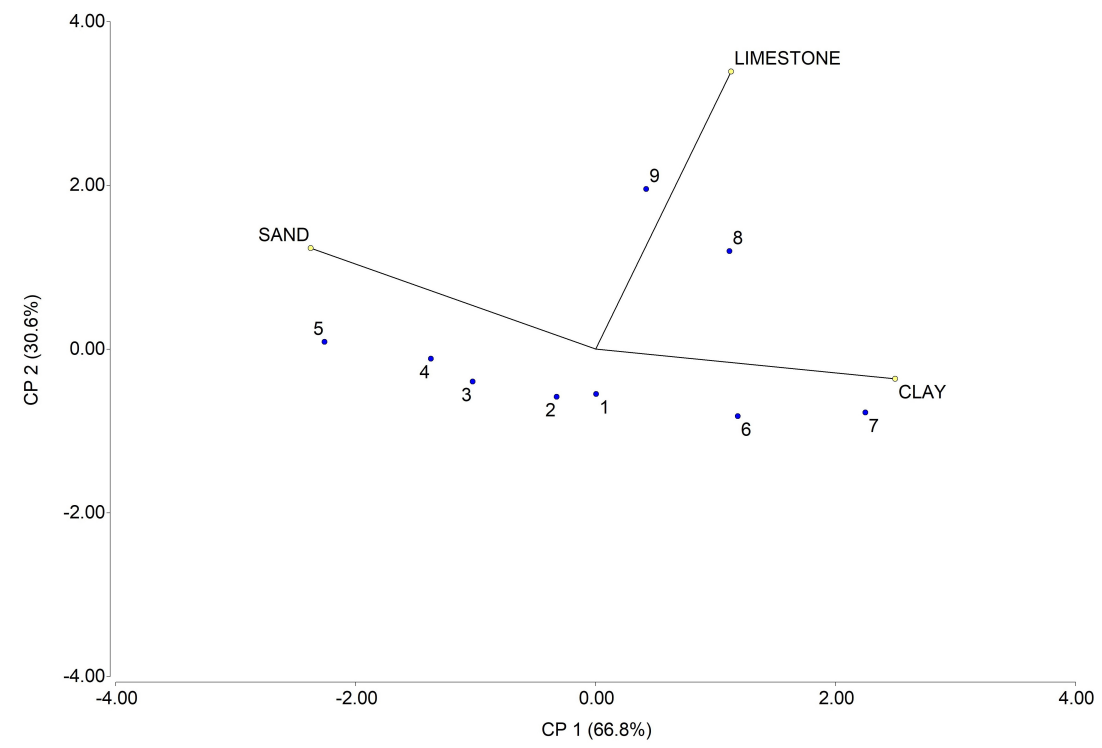

Figure A1. The two-dimensional principal subspace for the different textural soil percentages (correlation matrix PCA).

Table A1. Different compositional soils.

\begin{tabular}{cccc}
\hline Soil Sample & Sand (\%) & Clay (\%) & Limestone (\%) \\
\hline 1 & 59.8 & 20.4 & 3.1 \\
2 & 62.5 & 19.8 & 2.6 \\
3 & 63.7 & 16.4 & 2.8 \\
4 & 65.9 & 15.0 & 3.4 \\
5 & 75.3 & 13.7 & 2.9 \\
6 & 48.3 & 22.5 & 3.7 \\
7 & 39.5 & 24.5 & 5.1 \\
8 & 58.0 & 22.4 & 9.8 \\
9 & 62.5 & 19.3 & 11.7 \\
\hline
\end{tabular}

\section{Appendix B. KEGGs and Metabolism Pathways}

From the raw data, a functional estimation of the bacterial population was carried out using Tax4Fun (https://sourceforge.net/projects/Tax4Fun2/). This process allowed us to estimate the functional status of the plots studied with respect to winter and summer.

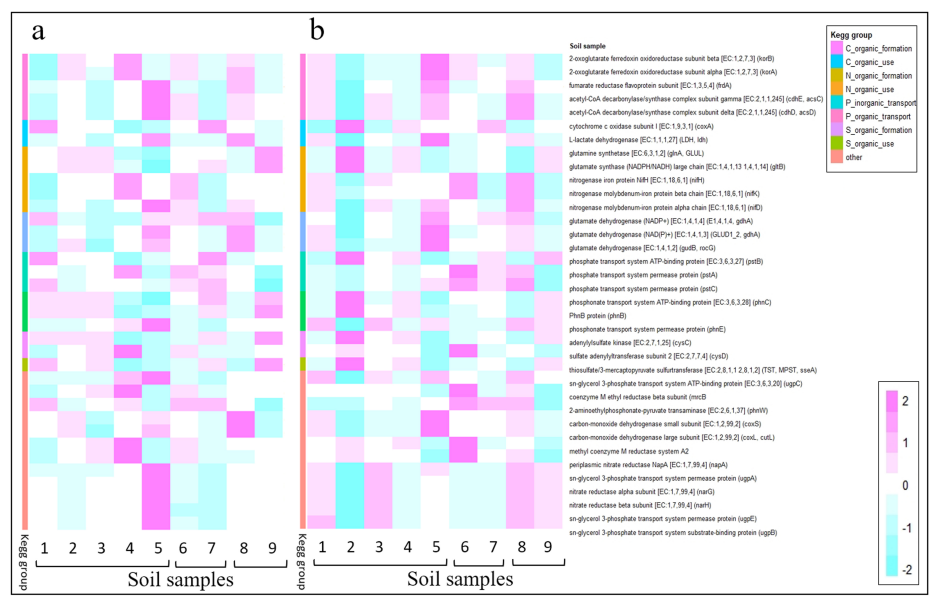

Figure A2. Functional prediction of bacterial populations in different season. Summer (a) and winter (b). 
Table A2. KEGG's table.

\begin{tabular}{|c|c|c|}
\hline KEGG & Functional Description: Name [EC] (gen) & Metabolism \\
\hline K02274 & cytochrome c oxidase subunit I [EC:1.9.3.1] (coxA) & Aerobic Respiration \\
\hline K00174 & 2-oxoglutarate ferredoxin oxidoreductase subunit alpha [EC:1.2.7.3] (korA) & Arnon Carbon Fixation \\
\hline K00175 & 2-oxoglutarate ferredoxin oxidoreductase subunit beta [EC:1.2.7.3] (korB) & Arnon Carbon Fixation \\
\hline K00244 & fumarate reductase flavoprotein subunit [EC:1.3.5.4] (frdA) & Arnon Carbon Fixation \\
\hline K00860 & adenylylsulfate kinase [EC:2.7.1.25] (cysC) & Assimilatory Sulfate Reduction \\
\hline K00957 & sulfate adenylyltransferase subunit 2 [EC:2.7.7.4] (cysD) & Assimilatory Sulfate Reduction \\
\hline K00016 & L-lactate dehydrogenase [EC:1.1.1.27] (LDH, ldh) & Fermentation \\
\hline K05816 & sn-glycerol 3-phosphate transport system ATP-binding protein [EC:3.6.3.20] (ugpC) & G3P Transporter \\
\hline K00400 & coenzyme Methyl reductase beta subunit $(\mathrm{mrcB})$ & Methanogenesis \\
\hline K00401 & methyl coenzyme $\mathrm{M}$ reductase system A2 & Methanogenesis \\
\hline K00265 & glutamate synthase (NADPH/NADH) large chain [EC:1.4.1.13, 1.4.1.14] (gltB) & Nitrogen Assimilation \\
\hline K01915 & glutamine synthetase [EC:6.3.1.2] (glnA, GLUL) & Nitrogen Assimilation \\
\hline K02588 & nitrogenase iron protein NifH [EC:1.18.6.1] (nifH) & Nitrogen Fixation \\
\hline K02591 & nitrogenase molybdenum-iron protein beta chain [EC:1.18.6.1] (nifK) & Nitrogen Fixation \\
\hline K00261 & glutamate dehydrogenase (NAD(P)+) [EC:1.4.1.3] (GLUD1 2, gdhA) & Nitrogen Mineralization \\
\hline K00262 & glutamate dehydrogenase (NADP+) [EC:1.4.1.4] (gdhA) & Nitrogen Mineralization \\
\hline K00260 & glutamate dehydrogenase [EC:1.4.1.2] (gudB, rocG) & Nitrogen Mineralization \\
\hline K02567 & periplasmic nitrate reductase NapA [EC:1.7.99.4] (napA) & Nitrogen Reduction \\
\hline K02036 & phosphate transport system ATP-binding protein [EC:3.6.3.27] (pstB) & Phosphate Transport High \\
\hline K02038 & phosphate transport system permease protein (pstA) & Phosphate Transport High \\
\hline K02037 & phosphate transport system permease protein (pstC) & Phosphate Transport High \\
\hline K03430 & 2-aminoethylphosphonate-pyruvate transaminase [EC:2.6.1.37] (phnW) & Phosphonate Metabolism \\
\hline K04750 & PhnB protein (phnB) & Phosphonate Transport \\
\hline K02041 & phosphonate transport system ATP-binding protein [EC:3.6.3.28] (phnC) & Phosphonate Transport \\
\hline K01011 & thiosulfate/3-mercaptopyruvate sulfurtransferase [EC:2.8.1.1, 2.8.1.2] (TST, MPST, sseA) & Sulfur Mineralitation \\
\hline
\end{tabular}

\section{Appendix C. Wine-Related Microorganism}

The following families of microorganisms have been used to define WRBs and WRFs. The presented data were elaborated from the description of these microorganisms in the bibliography.

Table A3. Wine-related microorganisms taxonomy.

\begin{tabular}{lllll}
\hline Kingdom & Phylum & Class & Order & Family \\
\hline Bacteria & Firmicutes & Bacilli & Bacillales & Bacillaceae \\
Bacteria & Firmicutes & Bacilli & Bacillales & Staphylococaceae \\
Bacteria & Firmicutes & Bacilli & Lactobacillales & Enterococcaceae \\
Bacteria & Firmicutes & Bacilli & Lactobacillales & Lactobacillaceae \\
Bacteria & Firmicutes & Bacilli & Lactobacillales & Leuconostocaceae \\
Bacteria & Firmicutes & Bacilli & Lactobacillales & Streptococcaceae \\
Bacteria & Proteobacteria & Alphaproteobacteria & Rhodospirillales & Acetobacteraceae \\
Fungi & Ascomycota & Saccharomycetes & Saccharomycetales & Debaryomycetaceae \\
Fungi & Ascomycota & Saccharomycetes & Saccharomycetales & Metschnikowiaceae \\
Fungi & Ascomycota & Saccharomycetes & Saccharomycetales & Pichiaceae \\
Fungi & Ascomycota & Saccharomycetes & Saccharomycetales & Saccharomycetaceae \\
Fungi & Basidiomycota & Tremellomycetes & Tremellales & Cryptococcaceae \\
\hline
\end{tabular}

* The information on the origin, occurrence and potential role of the wine related microorganisms (bacteria and yeasts) considered in this table can be found in the following references: Fleet (1993) [61]; König et al. (2009) [62]; Capozzi et al. (2011) [63]; and Benavent-Gil et al. (2016) [64].

\section{References}

1. Frąc, M.; Hannula, S.E.; Bełka, M.; Jẹdryczka, M. Fungal biodiversity and their role in soil health. Front. Microbiol. 2018, 9, 707. [CrossRef] [PubMed]

2. Isbell, F.I.; Polley, H.W.; Wilsey, B.J. Biodiversity, productivity and the temporal stability of productivity: Patterns and processes. Ecol. Lett. 2009, 12, 443-451. [CrossRef] [PubMed]

3. Jactel, H.; Gritti, E.; Drössler, L.; Forrester, D.; Mason, W.; Morin, X.; Pretzsch, H.; Castagneyrol, B. Positive biodiversity-productivity relationships in forests: Climate matters. Biol. Lett. 2018, 14, 20170747. [CrossRef] [PubMed] 
4. Balvanera, P.; Pfisterer, A.B.; Buchmann, N.; He, J.S.; Nakashizuka, T.; Raffaelli, D.; Schmid, B. Quantifying the evidence for biodiversity effects on ecosystem functioning and services. Ecol. Lett. 2006, 9, 1146-1156. [CrossRef] [PubMed]

5. Reed, H.E.; Martiny, J.B. Testing the functional significance of microbial composition in natural communities. FEMS Microbiol. Ecol. 2007, 62, 161-170. [CrossRef] [PubMed]

6. Maron, P.A.; Sarr, A.; Kaisermann, A.; Lévêque, J.; Mathieu, O.; Guigue, J.; Karimi, B.; Bernard, L.; Dequiedt, S.; Terrat, S.; et al. High microbial diversity promotes soil ecosystem functioning. Appl. Environ. Microbiol. 2018, 84, e02738-17. [CrossRef] [PubMed]

7. Van Der Heijden, M.G.; Bardgett, R.D.; Van Straalen, N.M. The unseen majority: Soil microbes as drivers of plant diversity and productivity in terrestrial ecosystems. Ecol. Lett. 2008, 11, 296-310. [CrossRef]

8. Allison, S.D.; Martiny, J.B. Resistance, resilience, and redundancy in microbial communities. Proc. Natl. Acad. Sci. USA 2008, 105, 11512-11519. [CrossRef]

9. Bardgett, R.D.; Van Der Putten, W.H. Belowground biodiversity and ecosystem functioning. Nature 2014, 515, 505. [CrossRef]

10. Maron, J.L.; Marler, M.; Klironomos, J.N.; Cleveland, C.C. Soil fungal pathogens and the relationship between plant diversity and productivity. Ecol. Lett. 2011, 14, 36-41. [CrossRef]

11. Katan, J. Diseases caused by soilborne pathogens: Biology, management and challenges. J. Plant Pathol. 2017, 99, 305-315.

12. Gilbert, J.A.; van der Lelie, D.; Zarraonaindia, I. Microbial terroir for wine grapes. Proc. Natl. Acad. Sci. USA 2014, 111, 5-6. [CrossRef] [PubMed]

13. Santos, A.; Marquina, D. Killer toxin of Pichia membranifaciens and its possible use as a biocontrol agent against grey mould disease of grapevine. Microbiology 2004, 150, 2527-2534. [CrossRef] [PubMed]

14. Karuppiah, V.; Li, T.; Vallikkannu, M.; Chen, J. Co-cultivation of Trichoderma asperellum GDFS1009 and Bacillus amyloliquefaciens 1841 causes differential gene expression and improvement in the wheat growth and biocontrol activity. Front. Microbiol. 2019, 10, 1068. [CrossRef] [PubMed]

15. Zarraonaindia, I.; Owens, S.M.; Weisenhorn, P.; West, K.; Hampton-Marcell, J.; Lax, S.; Bokulich, N.A.; Mills, D.A.; Martin, G.; Taghavi, S.; et al. The soil microbiome influences grapevine-associated microbiota. MBio 2015, 6, e02527-14. [CrossRef] [PubMed]

16. Cordero-Bueso, G.; Arroyo, T.; Serrano, A.; Valero, E. Remanence and survival of commercial yeast in different ecological niches of the vineyard. FEMS Microbiol. Ecol. 2011, 77, 429-437. [CrossRef] [PubMed]

17. Tello, J.; Cordero-Bueso, G.; Aporta, I.; Cabellos, J.; Arroyo, T. Genetic diversity in commercial wineries: Effects of the farming system and vinification management on wine yeasts. J. Appl. Microbiol. 2012, 112, 302-315. [CrossRef]

18. Capozzi, V.; Garofalo, C.; Chiriatti, M.A.; Grieco, F.; Spano, G. Microbial terroir and food innovation: The case of yeast biodiversity in wine. Microbiol. Res. 2015, 181, 75-83. [CrossRef]

19. Garofalo, C.; El Khoury, M.; Lucas, P.; Bely, M.; Russo, P.; Spano, G.; Capozzi, V. Autochthonous starter cultures and indigenous grape variety for regional wine production. J. Appl. Microbiol. 2015, 118, 1395-1408. [CrossRef]

20. De Celis, M.; Ruiz, J.; Martín-Santamaría, M.; Alonso, A.; Marquina, D.; Navascués, E.; Gómez-Flechoso, M.Á.; Belda, I.; Santos, A. Diversity of Saccharomyces cerevisiae yeasts associated to spontaneous and inoculated fermenting grapes from Spanish vineyards. Lett. Appl. Microbiol. 2019, 68, 580-588. [CrossRef]

21. Viel, A.; Legras, J.L.; Nadai, C.; Carlot, M.; Lombardi, A.; Crespan, M.; Migliaro, D.; Giacomini, A.; Corich, V. The geographic distribution of Saccharomyces cerevisiae isolates within three Italian neighboring winemaking regions reveals strong differences in yeast abundance, genetic diversity and industrial strain dissemination. Front. Microbiol. 2017, 8, 1595. [CrossRef] [PubMed]

22. Bokulich, N.A.; Collins, T.S.; Masarweh, C.; Allen, G.; Heymann, H.; Ebeler, S.E.; Mills, D.A. Associations among wine grape microbiome, metabolome, and fermentation behavior suggest microbial contribution to regional wine characteristics. MBio 2016, 7, e00631-16. [CrossRef] [PubMed]

23. Sirén, K.; Mak, S.S.T.; Fischer, U.; Hansen, L.H.; Gilbert, M.T.P. Multi-omics and potential applications in wine production. Curr. Opin. Biotechnol. 2019, 56, 172-178. [CrossRef] [PubMed] 
24. Belda, I.; Zarraonaindia, I.; Perisin, M.; Palacios, A.; Acedo, A. From vineyard soil to wine fermentation: Microbiome approximations to explain the "terroir" concept. Front. Microbiol. 2017, 8, 821. [CrossRef] [PubMed]

25. Raynaud, X.; Nunan, N. Spatial ecology of bacteria at the microscale in soil. PLoS ONE 2014, 9, e87217. [CrossRef] [PubMed]

26. Feld, L.; Nielsen, T.K.; Hansen, L.H.; Aamand, J.; Albers, C.N. Establishment of bacterial herbicide degraders in a rapid sand filter for bioremediation of phenoxypropionate-polluted groundwater. Appl. Environ. Microbiol. 2016, 82, 878-887. [CrossRef] [PubMed]

27. Albers, C.N.; Ellegaard-Jensen, L.; Hansen, L.H.; Sørensen, S.R. Bioaugmentation of rapid sand filters by microbiome priming with a nitrifying consortium will optimize production of drinking water from groundwater. Water Res. 2018, 129, 1-10. [CrossRef]

28. Becares, A.A.; Fernandez, A.F. Microbiome Based Identification, Monitoring and Enhancement Of Fermentation Processes and Products. US Patent Application 15/779,531, 20 December 2018.

29. Callahan, B.J.; McMurdie, P.J.; Rosen, M.J.; Han, A.W.; Johnson, A.J.A.; Holmes, S.P. DADA2: High-resolution sample inference from Illumina amplicon data. Nat. Methods 2016, 13, 581-583. [CrossRef]

30. Callahan, B.J.; Sankaran, K.; Fukuyama, J.A.; McMurdie, P.J.; Holmes, S.P. Bioconductor workflow for microbiome data analysis: From raw reads to community analyses. F1000Research 2016, 5, 1492. [CrossRef]

31. Callahan, B.J.; McMurdie, P.J.; Holmes, S.P. Exact sequence variants should replace operational taxonomic units in marker-gene data analysis. ISME J. 2017, 11, 2639. [CrossRef]

32. Quast, C.; Pruesse, E.; Yilmaz, P.; Gerken, J.; Schweer, T.; Yarza, P.; Peplies, J.; Glöckner, F.O. The SILVA ribosomal RNA gene database project: Improved data processing and web-based tools. Nucleic Acids Res. 2012, 41, D590-D596. [CrossRef] [PubMed]

33. Langille, M.G.; Zaneveld, J.; Caporaso, J.G.; McDonald, D.; Knights, D.; Reyes, J.A.; Clemente, J.C.; Burkepile, D.E.; Thurber, R.L.V.; Knight, R.; et al. Predictive functional profiling of microbial communities using 16S rRNA marker gene sequences. Nat. Biotechnol. 2013, 31, 814-821. [CrossRef] [PubMed]

34. Ortiz-Álvarez, R.; Fierer, N.; de los Ríos, A.; Casamayor, E.O.; Barberán, A. Consistent changes in the taxonomic structure and functional attributes of bacterial communities during primary succession. ISME J. 2018, 12, 1658. [CrossRef] [PubMed]

35. Aßhauer, K.P.; Wemheuer, B.; Daniel, R.; Meinicke, P. Tax4Fun: Predicting functional profiles from metagenomic 16S rRNA data. Bioinformatics 2015, 31, 2882-2884. [CrossRef] [PubMed]

36. McMurdie, P.J.; Holmes, S. phyloseq: An R package for reproducible interactive analysis and graphics of microbiome census data. PLoS ONE 2013, 8, e61217. [CrossRef] [PubMed]

37. Oksanen, J.; Blanchet, F.; Kindt, R.; Legendre, P.; Minchin, P.; O'Hara, R.; Simpson, G.; Solymos, P.; Stevens, M.; Wagner, H. Package “vegan." Community Ecol. Package 2013, 12, 1-295.

38. Shannon-Wiener, C.; Weaver, W.; Weater, W. The Mathematical Theory of Communication; EUA, University of Illinois Press: Champaign, IL, USA, 1949.

39. Bray, J.R.; Curtis, J.T. An ordination of the upland forest communities of southern Wisconsin. Ecol. Monogr. 1957, 27, 325-349. [CrossRef]

40. McMurdie, P.J.; Holmes, S. Waste not, want not: Why rarefying microbiome data is inadmissible. PLoS Comput. Biol. 2014, 10, e1003531. [CrossRef]

41. Di Rienzo, J.; Casanoves, F.; Balzarina, M.; Gonzalez, L.; Tablada, M.; Robledo, C. Infostat Versión 2018. Centro de Transferencia Infostat, FCA; Universidad Nacional de Córdoba: Córdoba, Argentina, 2018.

42. Stein, A.; Gerstner, K.; Kreft, H. Environmental heterogeneity as a universal driver of species richness across taxa, biomes and spatial scales. Ecol. Lett. 2014, 17, 866-880. [CrossRef]

43. Heino, J.; Melo, A.S.; Bini, L.M. Reconceptualising the beta diversity-environmental heterogeneity relationship in running water systems. Freshw. Biol. 2015, 60, 223-235. [CrossRef]

44. Dickens, S.; Allen, E.; Santiago, L.; Crowley, D. Exotic annuals reduce soil heterogeneity in coastal sage scrub soil chemical and biological characteristics. Soil Biol. Biochem. 2013, 58, 70-81. [CrossRef]

45. Weber, C.F.; King, G.M.; Aho, K. Relative abundance of and composition within fungal orders differ between cheatgrass (Bromus tectorum) and sagebrush (Artemisia tridentata)-associated soils. PloS ONE 2015, 10, e0117026. [CrossRef] [PubMed]

46. Horner-Devine, M.C.; Lage, M.; Hughes, J.B.; Bohannan, B.J. A taxa-area relationship for bacteria. Nature 2004, 432, 750-753. [CrossRef] [PubMed] 
47. Ranjard, L.; Dequiedt, S.; Prévost-Bouré, N.C.; Thioulouse, J.; Saby, N.; Lelievre, M.; Maron, P.; Morin, F.; Bispo, A.; Jolivet, C.; et al. Turnover of soil bacterial diversity driven by wide-scale environmental heterogeneity. Nat. Commun. 2013, 4, 1434. [CrossRef] [PubMed]

48. Peay, K.G.; Baraloto, C.; Fine, P.V. Strong coupling of plant and fungal community structure across western Amazonian rainforests. ISME J. 2013, 7, 1852. [CrossRef] [PubMed]

49. Venter, Z.S.; Jacobs, K.; Hawkins, H.J. The impact of crop rotation on soil microbial diversity: A meta-analysis. Pedobiologia 2016, 59, 215-223. [CrossRef]

50. He, J.; Tedersoo, L.; Hu, A.; Han, C.; He, D.; Wei, H.; Jiao, M.; Anslan, S.; Nie, Y.; Jia, Y.; et al. Greater diversity of soil fungal communities and distinguishable seasonal variation in temperate deciduous forests compared with subtropical evergreen forests of eastern China. FEMS Microbiol. Ecol. 2017, 93. [CrossRef]

51. Zhou, J.; Xia, B.; Huang, H.; Palumbo, A.V.; Tiedje, J.M. Microbial diversity and heterogeneity in sandy subsurface soils. Appl. Environ. Microbiol. 2004, 70, 1723-1734. [CrossRef]

52. Koranda, M.; Kaiser, C.; Fuchslueger, L.; Kitzler, B.; Sessitsch, A.; Zechmeister-Boltenstern, S.; Richter, A. Seasonal variation in functional properties of microbial communities in beech forest soil. Soil Biol. Biochem. 2013, 60, 95-104. [CrossRef]

53. Kaiser, C.; Fuchslueger, L.; Koranda, M.; Gorfer, M.; Stange, C.F.; Kitzler, B.; Rasche, F.; Strauss, J.; Sessitsch, A.; Zechmeister-Boltenstern, S.; et al. Plants control the seasonal dynamics of microbial N cycling in a beech forest soil by belowground C allocation. Ecology 2011, 92, 1036-1051. [CrossRef]

54. Gupta, V.V.S.R.; Bramley, R.G.V.; Greenfield, P.; Yu, J.; Herderich, M.J. Vineyard Soil Microbiome Composition Related to Rotundone Concentration in Australian Cool Climate 'Peppery' Shiraz Grapes. Front. Microbiol. 2019, 10, 1607. [CrossRef] [PubMed]

55. Kircher, M.; Kelso, J. High-throughput DNA sequencing-concepts and limitations. Bioessays 2010, 32, 524-536. [CrossRef] [PubMed]

56. Cappello, M.S.; Zapparoli, G.; Logrieco, A.; Bartowsky, E.J. Linking wine lactic acid bacteria diversity with wine aroma and flavour. Int. J. Food Microbiol. 2017, 243, 16-27. [CrossRef] [PubMed]

57. Sponholz, W.R. Wine spoilage by microorganisms. In Wine Microbiology and Biotechnology; Taylor \& Francis: Abingdon, UK, 1993; pp. 395-420.

58. Bartowsky, E.J.; Henschke, P.A. Acetic acid bacteria spoilage of bottled red wine-A review. Int. J. Food Microbiol. 2008, 125, 60-70. [CrossRef] [PubMed]

59. Chou, M.; Vanden, H.J.; Bell, T.; Panke-Buisse, K.; J, K.K. Vineyard under-vine floor management alters soil microbial composition, while the fruit microbiome shows no corresponding shifts. Sci. Rep. 2018, 8, e00631-16. [CrossRef] [PubMed]

60. Jackson, D.I.; Lombard, P.B. Environmental and Management Practices Affecting Grape Composition and Wine Quality-A Review. Am. J. Enol. Viticult. 1993, 44, 409-430.

61. Fleet, G.H. Wine Microbiology and Biotechnology; CRC Press: Boca Raton, FL, USA, 1993.

62. König, H.; Unden, G.; Fröhlich, J. Biology of Microorganisms on Grapes, in Must and in Wine; Springer: Berlin, Germany, 2009.

63. Capozzi, V.; Ladero, V.; Beneduce, L.; Fernández, M.; Alvarez, M.A.; Benoit, B.; Laurent, B.; Grieco, F.; Spano, G. Isolation and characterization of tyramine-producing Enterococcus faecium strains from red wine. Food Microbiol. 2011, 28, 434-439. [CrossRef] [PubMed]

64. Benavent-Gil, Y.; Berbegal, C.; Lucio, O.; Pardo, I.; Ferrer, S. A new fear in wine: Isolation of Staphylococcus epidermidis histamine producer. Food Control 2016, 62, 142-149. [CrossRef]

(C) 2019 by the authors. Licensee MDPI, Basel, Switzerland. This article is an open access article distributed under the terms and conditions of the Creative Commons Attribution (CC BY) license (http://creativecommons.org/licenses/by/4.0/). 